\title{
Enhanced performance for DRM over encapsulated structure catalyst with high dispersion of $\mathrm{Ni}$ in silicalite-2 shell
}

\author{
Yao $\mathrm{Lu}^{1}$, Dan Guo ${ }^{1}$, Yongzhe Ruan ${ }^{1}$, Yujun Zhao ${ }^{1}$, Shengping Wang ${ }^{1}$, and Xinbin Ma ${ }^{1}$ \\ ${ }^{1}$ Tianjin University
}

April 28, 2020

\begin{abstract}
Novel structure catalyst with $\mathrm{Ni}$ nanoparticles highly dispersed in silicalite-2 zeolite (S2) was designed and synthesized via a micro-emulsion method followed by solvent-free crystallization route for dry reforming of methane (DRM). Compared with $\mathrm{Ni}-\mathrm{SiO} 2$ catalyst without crystallization step, Ni/S2 by impregnation method and Ni@S2 prepared by directly crystallization (Ni@S2-O), the Ni@S2-two steps (Ni@S2-T) catalyst exhibited optimal catalytic activity and stability. No activity loss was observed during $70 \mathrm{~h}$ at high GHSV of $240000 \mathrm{~mL}$ g-1h-1. Meanwhile, Over spent Ni@S2-T catalyst, hardly any coke was found after the prolonged test, which indicated the remarkable anti-coking ability of Ni@S2-T. Thanks to the unique two-step synthetic processes, the confinement effect of the silicalite- 2 shell and stronger metal-support interaction causing by the formation of $\mathrm{Ni}$ phyllosilicate were regarded as the main reasons for superb catalytic performances.
\end{abstract}

\section{Hosted file}

Manuscript-0328.doc available at https://authorea.com/users/307863/articles/438811-enhancedperformance-for-drm-over-encapsulated-structure-catalyst-with-high-dispersion-of-ni-in-silicalite2-shell

\section{Hosted file}

Marked up Manuscript-0328.doc available at https://authorea.com/users/307863/articles/438811enhanced-performance-for-drm-over-encapsulated-structure-catalyst-with-high-dispersion-ofni-in-silicalite-2-shell 